anticipation has its realistic, cultural and neurotic determinants. The extent to which any one of these determinants contributes to the expectancy level probably varies considerably between social groups and personality types as well as longitudinally in one person. Carefully controlled studies are therefore necessary. The other major problem is that of measuring patients' expectancies. The author is aware of these difficulties and he presents a concise and fair exposition of the problems to date. The book carries a message for all doctors and is at the same time a stimulating source of information for interested research workers.

\section{Interhemispheric Relations and Cerebral Dominance}

Editor: Vernon B. Mountcastle. Pp. 294. Baltimore: The Johns Hopkins Press. 1962. Price not stated.

Although the conference, the proceedings of which are presented in this book, was concerned with the question: 'Why do we have two brains', only Professor $\mathrm{J}$. Z. Young in a stimulating and erudite contribution made any serious attempt to answer it. The remaining contributors contended themselves with the less ambitious task of presenting evidence of how the two hemispheres interact. They discussed the 'how' rather than the 'why'. Their contributions, nevertheless, make interesting reading; psychologists will value especially the contributions of Myers, Ettlinger and Downer on visual and somato-sensory integration; clinicians will enjoy Hecaen's account of his statistical assessments of the clinical symptomatology of lesions of each side of the brain. But as Young says in his admirable summing-up of the conference, the problem of cerebral dominance 'will demand the joint efforts of many generation s of scientists' before it yields its secret.

\section{Handbook of Pediatrics}

H. K. Silver, C. H. Kempe and W. B. Bruyn. Fifth edition. Pp. 62. Los Altos, California: Lange Medical Publications. 1963. \$4.

This American Handbook was first published in 1955 and has now entered its fifth edition. Three foreign language versions exist and two more are in preparation. The stated aim of the authors is to supplement the standard textbooks with ' a concise and readily available digest of the material necessary for the diagnosis and management of pediatric disorders '.

Most topics of pædiatric interest are covered adequately. Some features of the publication are commendable for example the numerous tables of information concerning growth, performance and pathology, also the diagrams illustrating some pædiatric procedures. The prominence given to pædiatric emergencies and to the management of poisoning in children is praiseworthy. Inevitably many American terms are used in the text, especially in the nomenclature of drugs. Some suggestions in the text are surprising, extreme examples are the instillation of $1 \%$ silver nitrate into the eyes of the newborn and the examination of frozen sections of umbilical cord for evidence of vasculitis. The description of a 'battered child syndrome', seems to be unnecessary and the statement that the complete examination of a child will include a routine W.R. will seem unusual in this country.

Although this is a handbook, nevertheless it comprises 602 pages of small type and is devoid of illustration apart from the diagrams to which reference has been made. The authors have succeeded in providing a portable and comprehensive source of information; they have not, however, been concise.
The Obstetrician, Anæsthetist and the Pædiatrician in the Management of Obstetric Problems

Edited by Trevor BarnetT and John JoyCE Foley. \$ Pp. xiii + 188, illustrated. Oxford, London, New York and Paris: Pergamon Press (Symposium.

Publications Division). 1963. 50s.

This is a nicely produced book and must serve as a splendid record for those who attended the conference. However, like all such records of the spoken word, the $\overline{\bar{O}}$ English has suffered and, in some cases, the meaning is $\frac{\bar{\sigma}}{\partial}$ not clear.

A number of the leading Obstetricians in the country took part and among them, Professor Duncan's remarks on domiciliary midwifery were pre-eminent. Professor $\overrightarrow{0}$ Donald's talk must have been a pleasure to listen to, when he spoke of resuscitation of the newborn.

Many speakers appear to be carried away by their $\vec{\omega}$ enthusiasm for their own methods and, where factual $\frac{D}{D}$ evidence was brought forward to support their claims, the conclusions were often mathematically faulty. A maternal mortality rate of $0.05 \%$ in the Dublin district could hardly be considered evidence of a successful selection of cases of good midwifery practice, but, $\vec{v}$ perhaps, there is a misprint here.

The discussion on resuscitation of the newborn was a reminder of the zeal shown for intra-gastric oxygen a $N$ few years ago and the answer to this problem surely, is $\frac{1}{\sigma}$ better obstetrics with no treatment required for an 윽 asphyxiated baby.

The book may be read with profit by independent $\vec{z}$ Obstetricians but could not be recommended for a $Z$ student or postgraduate, as the views expressed are often contradictory.

The general impression may give rise to the view that the care of the mother and her baby is passing from the Obstetrician to the Anæsthetist and Pædiatrician.

The Anatomical Foundation of Neruoradiology the Brain

McClure Wilson. Pp. $\mathrm{x}+239$, illustrated. London: J. \& A. Churchill. r963. £4 ros.

The teaching of anatomy to undergraduates is governed by the need to provide a wide view of the whole subject $\stackrel{\square}{\mathbb{Q}}$ and to make the general principles familiar. When the graduate decides to specialize he then has to go back to $\overrightarrow{\overrightarrow{0}}$ basic anatomy and physiology, and learn again in more detail those parts which are appropriate. This is particularly true of the anatomy of the brain.

Dr. McClure Wilson has provided the necessary review and additional details of cerebral and cerebrovascu- $\bar{\partial}$ lar anatomy needed by those who are studying neuro- 3 . radiology. There are chapters on the superficial an!tomy $\sigma$ of the brain, the venticular system, the subarachnoid 3 space and the arterial and venous systems, among others. It is an admirable, lucid, and accurate account of the structures demonstrated by various radiological techniques, $₹$ and ought to be read by any person learning the inter-을 pretation of cerebral angiograms and air studies. In this respect, it is a more valuable work of reference than $\frac{D}{O}$ the standard anatomical textbooks, in which the clinically important features are often obscured by detail or $N$ omitted altogether. The reproduction of x-rays is ex-の cellent, but some of the line drawings are a bit too freely $N$ diagrammatic. The index is satisfactory.

This book can unreservedly be recommended not $\mathrm{N}$ only to radiologists, but also to neurological and neurosurgical house staff whose final ambitions do not demand more detailed neuroanatomy, and should be available to all those who find the anatomy of the brain a land of $\mathbb{\Phi}$ mystery. It is to be hoped that a further volume on the? skull and spine will soon appear. 